\title{
Knowledge, Attitude and Practice Regarding Caries Risk Assessment and Management in General Dentists- A Cross Sectional Survey
}

\author{
Marzieh Karimi Afshar ${ }^{1}$, Molook Torabi $^{2}$, Elahe Khalafi ${ }^{3}$, Zahra Shamsadini ${ }^{4}$, Mehrnaz Karimi Afshar $^{5}$ \\ Iman Mohammadzadeh ${ }^{6}$
}

\begin{abstract}
${ }^{1}$ Kerman Social Determinants on Oral Health Research Center and Department of Orthodontics, School of Dentistry, Kerman University of Medical Sciences, Kerman, Iran. ${ }^{2}$ Department of Maxillofacial Pathology, Kerman Social Determinants of Oral Health Research Center and Oral and Dental Diseases Research Center and Kerman, School of Dentistry, Kerman University of Medical Sciences, Kerman, Iran. ${ }^{3}$ Dentist, School of dentistry, Kerman University of Medical Sciences, Kerman, Iran. ${ }^{4}$ Dentist, School of dentistry, Kerman University of Medical Sciences, Kerman, Iran. ${ }^{5}$ Department of Prosthodontics, School of Dentistry, Tehran University of Medical Sciences, Tehran, Iran. ${ }^{6}$ Oral and Dental Diseases Research Center, School of Dentistry, Kerman University of Medical Sciences, Kerman, Iran.
\end{abstract}

\section{ABSTRACT}

\section{BACKGROUND}

It is widely accepted that caries risk assessment (CRA) is the basis for management of dental caries in patients. The CRA can contribute to identifying people at high dental caries risk. The aim of this study was to assess the knowledge, attitude and practice of general dentists in the city of Kerman about CRA.

\section{METHODS}

The present descriptive cross-sectional study was conducted on 160 general dentists in the city of Kerman, Iran. Data collection tools consisted of demographic data and 10 questions of knowledge, 10 questions of practice, and 7 questions of attitude regarding the researcher-made CRA, whose validity and reliability have been measured previously. Data was analysed using SPSS software with ANOVA test at a significance level of 0.05 .

\section{RESULTS}

In this study, $55.6 \%$ were male. The mean age was $38.98 \pm 8.11$ years. The mean knowledge, practice and attitude score was $6.79 \pm 1.46,15.31 \pm 3.45$ and $11.25 \pm 1.64$ respectively. Female dentists had a significantly better practice. There was a statistically significant association between the positive response to participation in the courses of new methods of caries control with practice and attitude.

\section{CONCLUSIONS}

The level of knowledge and practice of individuals was inadequate; but, their attitude was appropriate. The practice of people on the introduction and application of anti-caries agents such as fluoride varnish and ACP-CPP, was inadequate. The knowledge on white spot as a caries lesion was poor. Training courses are recommended on the identification of initial caries lesions and their management via anti-caries agents.

\section{KEY WORDS}

Caries, Caries Risk Assessment, Knowledge, Attitude, Practice, Dentist
Corresponding Author:

Molook Torabi,

School of Dentistry,

Kerman University of Medical Sciences,

Kerman, Iran.

E-mail: m.torabi.p@gmail.com

DOI: 10.14260/jemds/2019/757

Financial or Other Competing Interests: None.

How to Cite This Article:

Afshar MK, Torabi M, Khalafi E, et al. Knowledge, attitude and practice regarding caries risk assessment and management in general dentists- a cross sectional survey. J. Evolution Med. Dent. Sci. 2019;8(47):3499-3504, DOI: 10.14260/jemds/2019/757

Submission 19-08-2019, Peer Review 07-11-2019,

Acceptance 13-11-2019,

Published 25-11-2019. 


\section{BACKGROUND}

Dental caries is a dynamic and multifactorial process.(1) Occurrence of dental caries is affected by several factors including oral microflora, quantity and composition of saliva, and patient-related parameters including general health and lifestyle, such as the use of fluoride-containing toothpastes and diet.(2) Caries risk is defined as the probability of developing caries in the future. The incidence of the disease can be either primary (New caries lesions) or secondary (Progression of lesion or reactivation of caries lesions).(1) Caries risk assessment (CRA) is the cornerstone for the successful application of a minimum intervention dentistry philosophy in the management of dental caries. Patients, especially those with evidence of active caries at the time of visit, require the CRA to identify the factors that are most likely to progress in the disease process. (3) The CRA is one of the foundations for managing the caries of patients.(4) Riley et al. showed that the anti-caries agents were widely used in private dentistry, while the CRA was performed by a few dentistry.(5) In a study of Gaskin et al., $63.5 \%$ of subjects agreed with the CRA.(6)

In a study of Shah et al., $36 \%$ of dentists agreed with the use of restorative materials and CRA-based methods, and $15.5 \%$ also strongly agreed with CRA for all patients.(7) In a study by Rayapudi and Usha, $81 \%$ of participants agreed with CRA in patients. ${ }^{(8)}$ In a study by Riley et al. about the use of CRA by dentists in children, $73 \%$ of dentists reported having CRAs for people aged 6 to 18 years. ${ }^{(9)}$ In another study by Riley et al., $69 \%$ of dentists performed CRA for patients, and $57 \%$ of dentists who performed CRA had considered an individualized caries prevention programs for their patients.(10) Hurlbutt et al. showed that caries management by the CRA is an example of patient care that has the best practice rather than traditional therapies.(11)

The CRA is a conservative approach that can prevent waste of time, energy and finances. Assessing the management of the consequences of illness in certain time periods leads to less waste of dental tissues. People's knowledge of CRA in patients leads to more conservative treatment. Due to limited studies in this field and the absence of research in this regard in Kerman, this study was conducted to evaluate the level of knowledge, practice and attitude of general dentists in the city of Kerman about CRA.

\section{METHODS}

The present descriptive cross-sectional study was conducted on general dentists in the city of Kerman, Iran, in 2019. The sample size was 160 , which was determined using the sample size formula-

$\left(n=\frac{z^{2} \times p(1-p)}{d^{2}}\right)$

$\mathrm{p}=0.5, \mathrm{~d}=0.08$

$\mathrm{z}=1.96$,

Through 340 general dentists in Kerman city. Data collection tools consisted of demographic data (including age, gender, graduation year, workplace, mean working hours per week, paediatric dentistry) and 27 questions for assessing knowledge, attitude and practice. The knowledge-related questions included 10 items about the knowledge of the CRA, whose method of answering was based on true and false options. Score 1 was attributed to the true answer and the 0 score to the false answer. Therefore, the score range $0-10$. Ten practice-related questions were based on the 4-point Likert scale, including always, often, sometimes and never. Therefore, the score range 0-30. Seven attitude-related questions were based on a 3-point Likert scale ("Agree", "Disagree" and "Neither agree nor disagree") with scores of 2,0 and 1, respectively. Therefore, the score range $0-14$. A researcher made this questionnaire based on texts and articles, whose validity was examined after reviewing and applying the views of the professors and setting the comments. The validity and reliability of the entire questionnaire were 0.89 and 0.81 , respectively. To do this, a trained senior in the dentist who was able to respond to the ambiguity referred to dentists. Following the explanation of study objectives and dentist's desire to respond, the questions were presented face to face to the dentist in their workplace and collected on the same day. The approximate response time was about 10 minutes. The questionnaires were unnamed and the participation in the project was voluntary. If the dentists were asking for the true answers, the questions were given to them. After collecting the completed questionnaires, the data were coded and entered into SPSS version 22, where they were analyzed using the descriptive statistics tools including mean, standard deviation, frequency, and percentage frequency and the analytical tests including chi-square test, two-sample t-test, and analysis of variance (ANOVA)and linear regression. The project proposal was approved by the Code of Ethics of IR.KMU.REC.1398.005 by the Ethics Committee of Kerman University of Medical Sciences.

\section{RESULTS}

Our research unites consisted of 71 (44.4\%) females and 89 $(55.6 \%)$ males. The mean age of the subjects was $38.89 \pm 8.11$, the mean working hours of the dentistry were $34.89 \pm 9.84$ hours per week and the mean graduation year was $10.89 \pm 5.85$ years.

Of the participants, 77 (48.1\%) worked only in the office and $50(31.3 \%)$ in both clinics and offices. The mean number of patients per week was between 20 and 30 in 81 (50.6\%). In addition, 115 (71.9\%) mentioned that they are doing work for children. In response to knowledge-related questions, $21.9 \%$ responded true answer to "Low socioeconomic status does not increase the caries risk" and $95.6 \%$ said the true answer to "reduced saliva flow increases caries risk" (Table 1). In the case of practice in the present study, 78.1\% always advised using fluoride toothpaste, and $58.1 \%$ always performed periodic examinations for patients. The least practice was in prescribing probiotics, so that $73.8 \%$ never prescribed probiotics (Table 2). Concerning the attitude of people in this study, $94.4 \%$ believed that the CRA is an important part of dental work, and $3.4 \%$ of people agreed that the CRA has no effect on dental caries control (Table 3). 
In addition, 152 (95\%) people recommended each person a caries prevention program based on their specific condition (Figure 1). The mean knowledge score was $1.46 \pm 6.79$ out of 10 , the mean practice score was $3.45 \pm 15.31$ out of 30 , and the mean attitude score was $1.64 \pm 11.25$ out of 14 . Female dentists had a significantly better practice $(\mathrm{p}=0.056)$. There was a statistically significant association between the positive response to participation in the courses of new methods of caries control with practice $(\mathrm{p}=0.51)$ and attitude $(\mathrm{p}=0.041)$. Regression analysis showed that there was a statistically significant association between the years of employment with attitude. Those who were newer graduated had a better attitude. Knowledge and practice had a statistically significant association (Table 5).

\begin{tabular}{|c|c|c|c|c|}
\hline \multirow{2}{*}{ Knowledge } & \multicolumn{2}{|c|}{ True } & \multicolumn{2}{|c|}{ False } \\
\hline & No. & $\%$ & No. & $\%$ \\
\hline Dental caries is a transmissible disease & 81 & 50.6 & 78 & 49.4 \\
\hline $\begin{array}{l}\text { A person with a history of carious lesions within the past } \\
1 \text { year is at a high risk for future dental caries activity }\end{array}$ & 140 & 87.5 & 20 & 12.5 \\
\hline $\begin{array}{l}\text { A person with a history of restorations within the past } 3 \\
\text { years is at a low risk for future dental caries activity }\end{array}$ & 37 & 23.1 & 123 & 76.9 \\
\hline White spot lesions are considered carious lesions & 63 & 39.4 & 97 & 60.6 \\
\hline Radiographic approximal lesions are disease indicators & 87 & 54.4 & 75 & 45.6 \\
\hline $\begin{array}{l}\text { Low-socioeconomic status does not increase an } \\
\text { individual's risk for dental caries disease }\end{array}$ & 35 & 21.9 & 125 & 78.1 \\
\hline Decreased saliva flow increases risk for dental caries & 153 & 95.6 & 7 & 4.4 \\
\hline $\begin{array}{l}\text { There is no evidence to support that twice a year or more } \\
\text { applications of fluoride varnish to reduce risk of carious } \\
\text { lesions in adults of high- caries risk }\end{array}$ & 36 & 22.5 & 124 & 77.5 \\
\hline $\begin{array}{l}\text { Patients at moderate or high risk of dental caries need to } \\
\text { be counselled about the role of sugary and starchy foods } \\
\text { in increasing caries risk }\end{array}$ & 156 & 97.5 & 4 & 2.5 \\
\hline $\begin{array}{c}\text { Chlorhexidine is known to kill all caries pathogenic } \\
\text { organisms }\end{array}$ & 96 & 60.0 & 64 & 40.0 \\
\hline 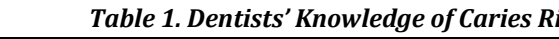 & & & & \\
\hline
\end{tabular}

\begin{tabular}{|c|c|c|c|c|c|c|c|c|}
\hline \multirow{2}{*}{ Practice } & \multicolumn{1}{|c|}{ Never } & \multicolumn{10}{|c|}{ Occasionally } & \multicolumn{2}{c|}{ Often } & \multicolumn{2}{c|}{ Always } \\
\cline { 2 - 10 } & No. & $\%$ & No. & $\%$ & No. & $\%$ & No. & $\%$ \\
\hline Fluoridated toothpaste & 3 & 1.9 & 4 & 2.5 & 28 & 17.5 & 125 & 78.1 \\
\hline Low-dose OTC fluoriderinse & 10 & 6.3 & 33 & 20.6 & 57 & 35.6 & 60 & 37.5 \\
\hline Topical fluoride applications (varnishes/gels) & 33 & 20.6 & 89 & 55.6 & 28 & 17.5 & 10 & 6.3 \\
\hline Amorphous calcium phosphateproducts & 91 & 56.9 & 55 & 34.4 & 13 & 8.1 & 1 & 0.6 \\
\hline Antimicrobial rinse & 16 & 10.0 & 96 & 60.0 & 47 & 28.4 & 1 & 0.6 \\
\hline Probiotics & 118 & 73.8 & 27 & 16.9 & 14 & 9.4 & - & - \\
\hline Diet counseling & 28 & 17.5 & 64 & 40.0 & 49 & 30.6 & 19 & 11.9 \\
\hline Individualized oral hygiene instructions & 3 & 1.9 & 11 & 6.9 & 67 & 41.9 & 80 & 49.4 \\
\hline Individualized recare/recall interval & 0 & 0 & 8 & 5.0 & 59 & 36.9 & 93 & 58.1 \\
\hline Xylitol chewinggum & 42 & 26.3 & 66 & 41.3 & 41 & 25.6 & 11 & 6.9 \\
\hline Table 2. Dentists' Practice of Caries Risk Assessment \\
\hline
\end{tabular}

\begin{tabular}{|c|c|c|c|c|c|c|}
\hline \multirow{2}{*}{ Attitude } & \multicolumn{2}{|c|}{ Agree } & \multicolumn{2}{|c|}{ No Idea } & \multicolumn{2}{|c|}{ Disagree } \\
\hline & No. & $\%$ & No. & $\%$ & No. & $\%$ \\
\hline Performing CRA is an integral part of dental practice & 151 & 94.4 & 9 & 5.6 & - & - \\
\hline Caries management involves providing dental restorations & 121 & 75.6 & 35 & 21.9 & 4 & 2.5 \\
\hline I have enough time to perform CRA on each patient & 120 & 75.0 & 32 & 20.0 & 8 & 5.0 \\
\hline I am confident in my ability to explain CRA results to the patient & 100 & 62.6 & 50 & 31.3 & 10 & 6.3 \\
\hline CRA is more effective in children below 5 years & 28 & 17.5 & 85 & 53.1 & 29 & 18.1 \\
\hline CRA is more effective in $12-18$ years age group & 110 & 68.8 & 49 & 30.6 & 1 & 0.6 \\
\hline CRA is not effective in dental caries control & 7 & 3.4 & 28 & 17.5 & 125 & 78.1 \\
\hline \multicolumn{7}{|c|}{ Table 3. Dentists 'Attitude about CRA } \\
\hline
\end{tabular}

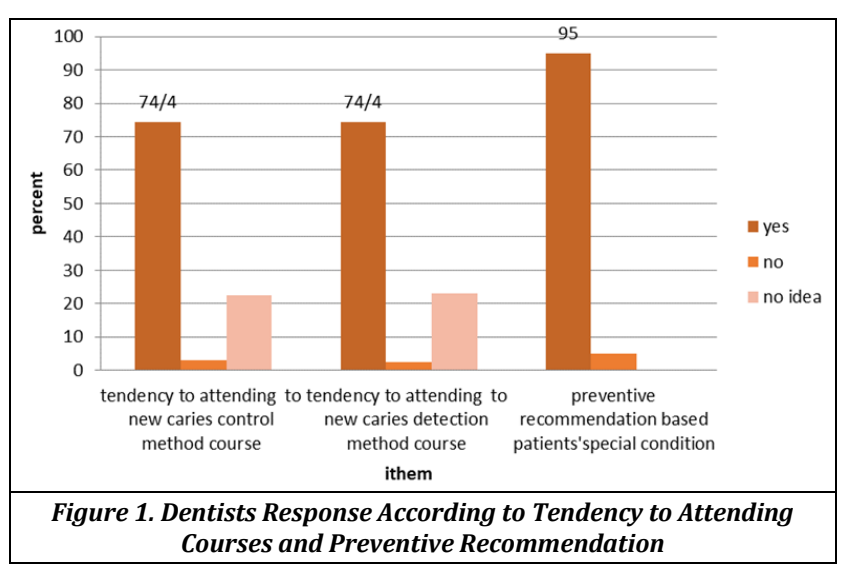

\begin{tabular}{|c|c|c|c|c|c|}
\hline \multicolumn{3}{|c|}{ Variables } & Mean & & p \\
\hline \multirow{10}{*}{$\begin{array}{l}0 \\
\frac{0}{0} \\
\frac{0}{3} \\
0 \\
\dot{z}\end{array}$} & \multirow{2}{*}{ gender } & men & 6.65 & 1.48 & \multirow{2}{*}{0.160} \\
\hline & & women & 7.00 & 1.40 & \\
\hline & \multirow{3}{*}{$\begin{array}{l}\text { Tendency to attending to new } \\
\text { caries control method course }\end{array}$} & no & 6.25 & 0.95 & \multirow{3}{*}{0.488} \\
\hline & & No idea & 7.01 & 1.20 & \\
\hline & & yes & 6.76 & 1.52 & \\
\hline & \multirow{3}{*}{$\begin{array}{l}\text { Tendency to attending to new } \\
\text { caries detection method course }\end{array}$} & no & 6.66 & 0.57 & \multirow{3}{*}{0.768} \\
\hline & & No idea & 6.96 & 1.33 & \\
\hline & & yes & 6.76 & 1.50 & \\
\hline & \multirow{2}{*}{$\begin{array}{c}\text { Preventive recommendation } \\
\text { based patients 'special condition }\end{array}$} & yes & 6.81 & 1.45 & \multirow{2}{*}{0.662} \\
\hline & & no & 6.50 & 1.64 & \\
\hline \multirow{10}{*}{ 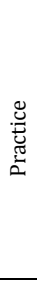 } & \multirow{2}{*}{ gender } & men & 14.83 & 3.66 & \multirow{2}{*}{$0.056^{*}$} \\
\hline & & women & 15.94 & 3.00 & \\
\hline & \multirow{3}{*}{$\begin{array}{l}\text { Tendency to attending to new } \\
\text { caries control method course }\end{array}$} & no & 14.00 & 1.00 & \multirow{3}{*}{$0.051^{*}$} \\
\hline & & No idea & 14.09 & 3.55 & \\
\hline & & yes & 15.71 & 3.38 & \\
\hline & \multirow{3}{*}{$\begin{array}{l}\text { Tendency to attending to new } \\
\text { caries detection method course }\end{array}$} & No & 14.00 & 1.00 & \multirow{3}{*}{$0.045^{*}$} \\
\hline & & No idea & 14.17 & 3.55 & \\
\hline & & yes & 15.73 & 3.44 & \\
\hline & \multirow{2}{*}{$\begin{array}{c}\text { Preventive recommendation } \\
\text { based patients' special condition }\end{array}$} & yes & 15.37 & 3.49 & \multirow{2}{*}{0.482} \\
\hline & & No & 14.42 & 2.82 & \\
\hline \multirow{10}{*}{ 莺 } & \multirow{2}{*}{ Gender } & men & 11.14 & 1.61 & \multirow{2}{*}{0.431} \\
\hline & & women & 11.35 & 1.68 & \\
\hline & \multirow{3}{*}{$\begin{array}{l}\text { Tendency to attending to new } \\
\text { caries control method course }\end{array}$} & No & 9.25 & 1.50 & \multirow{3}{*}{$0.041^{*}$} \\
\hline & & No idea & 11.17 & 1.74 & \\
\hline & & yes & 11.33 & 1.58 & \\
\hline & \multirow{3}{*}{$\begin{array}{l}\text { Tendency to attending to new } \\
\text { caries detection method course }\end{array}$} & No & 8.66 & 1.15 & \multirow{3}{*}{$0.013^{*}$} \\
\hline & & No idea & 11.05 & 1.68 & \\
\hline & & yes & 11.37 & 1.59 & \\
\hline & \multirow{2}{*}{$\begin{array}{c}\text { Preventive recommendation } \\
\text { based patients' special condition }\end{array}$} & yes & 11.32 & 1.61 & \multirow{2}{*}{$0.06^{*}$} \\
\hline & & no & 10.00 & 2.09 & \\
\hline
\end{tabular}

Table 4. Correlation between Knowledge, Practice and Attitude of Participants According to Gender and Tendency to Attend New Caries Control and Diagnosis Method Course

\begin{tabular}{|c|c|c|c|c|c|}
\hline \multicolumn{2}{|c|}{ Variables } & B & Beta & t & p Value \\
\hline \multirow{4}{*}{ Knowledge } & age & -0.091 & -0.420 & -2.547 & 0.013 \\
\cline { 2 - 6 } & Occupational years & 0.080 & 0.300 & 1.822 & 0.072 \\
\cline { 2 - 6 } & Doing paediatric dentistry & -0.655 & -0.190 & -1.862 & 0.066 \\
\cline { 2 - 6 } & Practice & 0.096 & 0.221 & 2.184 & 0.032 \\
\hline Practice & Knowledge & 0.529 & 0.228 & 2.184 & 0.032 \\
\hline \multirow{2}{*}{ Attitude } & age & 0.109 & 0.442 & 2.628 & 0.010 \\
\cline { 2 - 6 } & Occupational years & -0.158 & -0.522 & -3.105 & 0.003 \\
\hline
\end{tabular}

Table 5. Correlation between Demographic Variables with Knowledge, Attitude and Practice

\section{DISCUSSION}

According to current care standards, the individualized caries prevention and treatment programs should be performed for each patient.(12) The present study was aimed at assessing the level of knowledge, attitude and practice of dentists based on CRA and its management. In this study, $6.87 \%$ of people believed that "people with history of restoration in a past year are at high risk for future caries activity." Goswami et al.(13) stated that $88.7 \%$ of people had answered the true answer to this question. In the current study, only $39.4 \%$ of people considered white spot as caries lesions. In the study of Goswami et al., $49.8 \%$ of dentists considered white points as a caries lesion, which is more than the current study. The reason for this difference is that Goswami et al. also examined paediatric dentists.(13) The inability of dentists to detect this stage can prevent the offer of minimal invasion services with the aim of dental remineralization. Therefore, the knowledge of white spots and their management is essential.

In addition, $21.9 \%$ of the participants in this study responded true answer to "Low socioeconomic status increases the caries risk". In the study of Goswami et al.(13) $35.3 \%$ responded true answer. Goldfeld et al. showed that caries were higher in children with lower socioeconomic status.(14) Factors such as the socioeconomic status represent a few key indicators of the disease, such as the socioeconomic status, and risk factors such as microflora determines that the 
person is at a low, moderate and high risk of caries, although most of the research has been carried out on children.(15) The CRA is more important in people who have inadequate socioeconomic status and further attention should be paid to this group of people. In the current study, $40.0 \%$ did not believe that "chlorhexidine would eliminate caries-causing microbes." The result is consistent with the study of Goswami et al., so that $35.6 \%$ of people gave the true answer.(13)

A systematic study of clinical trials showed that chlorhexidine was more effective in preventing caries and reducing Streptococcus mutans in children and adolescents than in placebo or in the absence of treatment. The authors recommended the need for high-quality research, especially on the effects of chlorhexidine on permanent and deciduous teeth and the use of other oral products containing chlorhexidine.(16)

In a study of Autio-Gold and Tomar, most dental students tended to use chlorhexidine to control caries.(17) In the current study, $73.8 \%$ of people never prescribed probiotics, which is almost consistent with the study of Goswami et al., in which $60.7 \%$ never prescribed probiotics.(13) Probiotics are microorganisms that are useful when they are administered in sufficient quantities.(18)

The mechanism of action of probiotics in the mouth is not well defined, but it has been associated with a decrease in CFUs of caries-causing pathogens.(19) In a systematic review regarding the effects of probiotics in published articles with a high impact factor, it was shown that probiotics had the ability to reduce $S$. mutans in saliva and plaque in the short term in two thirds of the articles.(20) Villavicencio et al. showed that administration of probiotics significantly reduced lactobacilli in preschool children.(21) In this study, $56.9 \%$ of participants never prescribed a casein phosphopeptide-amorphous calcium phosphate (CPP-ACP) for their patients.

Goswami et al. showed that $25.5 \%$ of dentists never prescribed CPP-ACP, which is far less than the current study. The reason for this difference is that research units in their study included paediatric dentists.(13)

Asokan et al. in a systematic study showed that CPP-ACP had a positive effect on remineralization of white spot lesions. (22)

It was also shown that the CPP-ACP has a greater effect on enamel remineralization than other materials that have the potential for enamel remineralization.(23) Due to the positive effect of these materials on enamel remineralization, it seems that more focus should be put on the introduction and role of these products in order to publicize their application. In this study, nutritional counseling was given to patients as always only by $11.9 \%$ of cases and as sometimes by $40 \%$. Studies show increased caries with sugar consumption.(24) Given the evidence of the effect of drinking and sweet foods on caries, further attention is recommended for the nutritional counseling to patients, including reduced consumption of sweets and sweet snacks.

In this study, the dentists always recommended mouthwash and gel/fluoride varnish by $37.5 \%$ and $6.2 \%$, respectively. In the study of Riley, the use of fluoride in office with $82 \%$ was the most commonly used method of preventing caries in children. The use of over the counter (OTC) fluoride was also higher, which is consistent with the current study.(25) For patients at high or severe risk for caries, the importance of using sealants and fluoride varnish should be emphasized approximately 2-4 times a year.(26)

In a study by Yoder et al. in India, 91\% of dentists always or usually prescribed fluoride for children with active caries. (27) In this study, $6.9 \%$ of people always prescribed xylitolcontaining chewing gum for patients. In the study of Goswami et al., $4 \%$ of dentists often prescribed xylitol-containing chewing gum for their patients.(13) In a clinical trial on adolescents aged 14-15 years, it was shown that plaque and gingival bleeding were significantly decreased in people who used sugar-free chewing gum versus control subjects.(28)

Evidence supports the use of xylitol as an anti-caries treatment. It seems that xylitol-containing chewing gum is a good choice to stimulate saliva through the act of chewing.(29) Given the positive effects of sugar-free chewing gum, it seems that administration of this proper and useful ingredient in caries control by dentists is inappropriate and inadequate, and more attention should be paid to this. In this research, $94.4 \%$ of the people agreed that the CRA was part of the process of dental work. These results are consistent with the study of Goswami et al., with $94 \%$ of the subjects agreeing with the CRA.(13)

In this study, $75.6 \%$ of people agreed that CRA is one of the major issues in the management of caries in the choice of restorations. In the study of Goswami et al., $84.7 \%$ of people agreed as well.(13) The reason for this could be that the paediatric dentists also participated in the study of Goswami et al.

In this study, $75.0 \%$ of people mentioned that they had enough time to do the CRA. In the study of Goswami et al., $36.7 \%$ of the subjects had enough time for CRA.(13) In the current study, $95.0 \%$ of people recommended each patient for a caries prevention program based on their specific condition. In a study by Nagaraj et al.(30) $24.91 \%$ of individuals performed the CRA for each patient. The reason for these differences can be attributed to the type of study and the method of assessment. In the present study, 78.1\% believed that the CRA was effective in controlling caries. Considering that $75.0 \%$ of people mentioned that they had enough time for CRA, it could be hoped that the CRA could be effective in reducing caries in Kerman. In this study, 74.4\% of people tended to participate in training courses on new ways to control caries.

There was a statistically significant association between the positive response to participation in the courses of new methods of caries control with practice $(0.051)$ and attitude $(p=0.041)$. Regarding the interest of individuals in this regard, inclusion of these courses in retraining programs and conferences is recommended.

In the present study, there was a marginally significant association between the attitude of dentists in Kerman and having a caries prevention program based on the specific condition of each patient. The first step in the CRA process is to consider the caries risk in each patient, which means that the probability of a new caries lesion during a particular period and the likelihood of a change in the size or activity of the existing lesions will be determined over time.(31,32)

Female dentists had a significantly better practice. The reason for this is that female dentists work more with children.

In the present study, knowledge has a direct and significant association with practice. Higher knowledge 
shows better practice. Accordingly, it seems that conducting classes and courses focusing on the recognition of dental caries and the importance of CRA can lead to controlling the caries of individuals and identifying people at high caries risk. Newer graduates had a better attitude that could be due to learning new CRA content and familiarizing themselves with newer methods of caries control.

\section{CONCLUSIONS}

Given the importance of CRA in identifying people with high caries risk, managing the initial caries lesions and reducing new caries, which are important objectives of CRA program, the knowledge and practice of individuals in this study were inadequate, but their attitude was appropriate. The practice of people, especially on the introduction and application of anti-caries agents such as fluoride varnish and ACP-CPP, was inadequate. The knowledge of participants was poor on white spot as a caries lesion. Training courses are recommended on the identification of initial caries lesions and their management via anti-caries agents.

\section{ACKNOWLEDGEMENT}

The authors, hereby, would like to thank the Research Deputy of Kerman University of Medical Sciences for approval.

\section{REFERENCES}

[1] Frencken JE, Peters MC, Manton DJ, et al. Minimal intervention dentistry for managing dental caries - a review: report of a FDI task group. Int Dent J 2012;62(5):223-43.

[2] Marsh PD. Microbiology of dental plaque biofilms and their role in oral health and caries. Dent Clin North Am 2010;54(3):441-54.

[3] Hallett KB. The application of caries risk assessment in minimum intervention dentistry. Aust Dent J 2013;58 Suppl 1:26-34.

[4] Twetman S, Fontana M. Patient caries risk assessment. Monographs in Oral Science 2009;21:91-101.

[5] Riley JL 3rd, Gordan VV, Rindal DB, et al. Preferences for caries prevention agents in adult patients: findings from the dental practice-based research network. Community Dent Oral Epidemiol 2010;38(4):360-70.

[6] Gaskin EB, Levy S, Guzman-Armstrong S, et al. Knowledge, attitudes and behaviors of federal service and civilian dentists concerning minimal intervention dentistry. Mil Med 2010;175(2):115-21.

[7] Shah AH, Sheddi FM, Alharqan MS, et al. Knowledge and attitude among general dental practitioners towards minimally invasive dentistry in Riyadh and AlKharj. J Clin Diagn Res 2016;10(7):ZC90-4.

[8] Rayapudi J, Usha C. Knowledge, attitude and skills of dental practitioners of Puducherry on minimally invasive dentistry concepts: a questionnaire survey. J Conserv Dent 2018;21(3):257-62.

[9] Riley JL 3rd, Qvist V, Fellows JL, et al. Dentists' use of caries risk assessment in children: findings from the Dental Practice-Based Research Network. Gen Dent 2010;58(3):230-4.

[10] Riley JL 3rd, Gordan VV, Ajmo CT, et al. Dentists' use of caries risk assessment and individualized caries prevention for their adult patients: Findings from The Dental Practice-Based Research Network. Tex Dent J 2015;132(1):18-29.

[11] Hurlbutt M, Young DA. A best practices approach to caries management. J Evid Based Dent Pract 2014;(Suppl 14):77-86.

[12] Young DA, Featherstone JD, Roth JR, et al. Caries management by risk assessment: implementation guidelines. J Calif Dent Assoc 2007;35(11):799-805.

[13] Goswami M, Sachdeva P, Paul S, et al. Knowledge, attitude and practice regarding caries risk assessment and management in Delhi - National Capital Region: a cross-sectional survey. J Indian Assoc Public Health Dent 2016;14(2):188-96.

[14] Goldfeld S, Francis KL, Hoq M, et al. The impact of policy modifiable factors on inequalities in rates of child dental caries in Australia. Int J Environ Res Public Health 2019;16(11). pii: E1970.

[15] Zero D, Fontana M, Lennon AM. Clinical applications and outcomes of using indicators of risk in caries management. J Dent Educ 2001;65(10):1126-32.

[16] Walsh T, Oliveira-Neto JM, Moore D. Chlorhexidine treatment for the prevention of dental caries in children and adolescents. Cochrane Database Syst Rev 2015;(4):CD008457.

[17] Autio-Gold JT, Tomar SL. Dental students' opinions and knowledge about caries management and prevention. Journal of Dental Education 2008;72(1):26-32.

[18] World Health Organization - WHO. Food and Agriculture Organization of the United Nations. Guidelines for the evaluation of probiotics in food: report of a joint FAO/WHO working group on drafting guidelines for the evaluation of probiotics in food. London Ontario: The Organization, 2002. [Cited 2018 Jan 19].

http://www.who.int/foodsafety/fs_management/en/ probiotic_guidelines.pdf.

[19] Seminario-Amez M, López-López J, Estrugo-Devesa A, et al. Probiotics and oral health: a systematic review. Med Oral Patol Oral Cir Bucal 2017:22(3):e282-8.

[20] Cagetti MG, Mastroberardino S, Milia E, et al. The use of probiotic strains in caries prevention: a systematic review. Nutrients 2013;5(7):2530-50.

[21] Villavicencio J, Villegas LM, Arango MC, et al. Effects of a food enriched with probiotics on Streptococcus mutans and Lactobacillus spp. salivary counts in preschool children: a cluster randomized trial. J Appl Oral Sci 2018;26:e20170318.

[22] Asokan S, Geethapriya PR, Vijayasankari V. Effect of nonfluoridated remineralizing agents on initial enamel carious lesions: a systematic review. Indian J Dent Res 2019;30(2):282-90. 
[23] Ekambaram M, Mohd Said SNB, Yiu CKY. A review of enamel remineralisation potential of calcium- and phosphate-based remineralisation systems. Oral Health Prev Dent 2017;15(5):415-20.

[24] Chi DL, Hopkins S, O'Brien D, et al. Association between added sugar intake and dental caries in Yup'ik children using a novel hair biomarker. BMC Oral Health 2015;15(1):121.

[25] Riley JL, Richman JS, Rindal DB, et al. Use of cariespreventive agents in children: findings from the dental practice-based research network. Oral Health Prev Dent 2010;8(4):351-9.

[26] Wong A, Subar PE, Young DA. Dental caries an update on dental trends and therapy. Advances in Paediatrics 2017;64(1):307-30.

[27] Yoder KM. Indiana's dental workforce: distribution and related issues. J Indiana Dent Assoc 2007;86(2):10-3, 15.
[28] Saheer PA, Parmar P, Majid SA, et al. Effect of sugarfree chewing gum on plaque and gingivitis among 1415-year-old school children: a randomized controlled trial. Indian J Dent Res 2019;30(1):61-6.

[29] Salli KM, Forssten SD, Lahtinen SJ, et al. Influence of sucrose and xylitol on an early Streptococcus mutans biofilm in a dental simulator. Arch Oral Biol 2016;70:39-46.

[30] Nagaraj A, Vishnani P, Yousuf A, et al. Perception of dentists about caries-risk assessment tools in Jaipur, India: a cross-sectional study. Journal of International Oral Health 2015;7(8):77-81.

[31] American Academy of Paediatric Dentistry. Guideline on caries-risk assessment and management for infants, children and adolescents. Reference Manual, Paediatr Dent 2011;33(6):110-5.

[32] Celik EU, Gokay N, Ates M. Efficiency of caries risk assessment in young adults using Cariogram. Eur J Dent 